\title{
DAMPAK LINGKUNGAN ORGANISASI DAN GAYA KEPEMIMPINAN TERHADAP KEPUASAN KERJA PETUGAS LAYANAN KESEHATAN (STUDI KASUS RUMAH SAKIT KOTA CIMAHI)
}

\author{
Sriwardani $^{1 *}$, Rizky Ferrari ${ }^{2}$, Fitriani Fajar $^{3}$ \\ 1. Pusat Pengembangan Karir (PPK), Fakultas Ekonomi Dan Bisnis, \\ Universitas Langlangbuana Bandung, Indonesia \\ 2. Universitas Langlangbuana Bandung, Indonesia \\ 3. STIA Bagasasi Bandung, Indonesia \\ *e-mail: $\underline{\text { sriwardani@unla.ac.id }}^{\mathbf{1}}, \underline{\text { rzky.ferari@unla.ac.id }}^{\mathbf{2}}$, fitriani.fajar@bagasasi.ac.id $^{\mathbf{3}}$
}

\begin{abstract}
Penelitian ini bertujuan untuk mengetahui pengaruh lingkungan kerja dan gaya kepemipinan terhadap kepuasan kerja karyawan di Rumah Sakit di kota Cimahi. Penelitian ini menggunakan pendekatan desktiptif verifikatif, dan 91 karyawan menjadi sampel dengan menggunakan analisis regresi berganda yang dibantu oleh software SPSS 23. Data primer dari penelitian ini diperoleh dari kuestioner dan wawancara. Sementara data sekunder diperoleh melalui catatan dan publikasi serta literature. Hasil penelitian menunjukkan bawah terdapat pengaruh antara variabel lingkungan kerja dan gaya kepemimpinan terhadap kepuasan kerja karyawan pada Rumah Sakit layanan kesehatan. Pengaruh lingkungan kerja memberikan pengaruh terhadap kepuasan kerja karyawan sehingga karyawa berkomitmen dan lyal terhadaporganisasi. Sedangkan gaya kepemimpinan yang baik dapat meningkatkan kepuasan kerja karyawan semakin meningkat. Hal ini juga dibuktikan dengan nilai Adjusted $R$ Square sebesar 0,571 atau sebesar $57,1 \%$.
\end{abstract}

Keywords: Lingkungan organisasi, Gaya kepemimpinan, Kepuasan kerja

\section{PENDAHULUAN}

Dalam menghadapi persaingan bisnis yang kompetitif baik dalam sektor manufaktur ataupun jasa, menuntut pada setiap organisasi untuk mengelola sumber dayanya dengan baik sehingga menghasilkan keunggulan bersaing (Wei, H dan Sewell, K, 2018). Profitabilitas yang berkelanjutan dari suatu organisasi akan sangat tergantung pada kepuasan kerja tenaga kerja dan komitmen organisasi. sehingga pada akhirnya, kepuasan kerja karyawan dapat meningkatkan motivasi, kinerja, dan mengurangi turn-over yang tinggi. Menurut Bakoti, D (2016) Kepuasan kerja adalah sikap karyawan tentang pekerjaannya terhadap organisasi tempat dia melakukan pekerjaan itu. Hoboubi, N et al (2017) menyebutkan bahwa kepuasan kerja sangat berkorelasi dengan gaji yang diterima, tunjangan,pengakuan, promosi, rekan kerja, dukungan manajemen, kondisi kerja, gaya kepemimpinan dsb. Bohlander, S (2013) merangkum beberapa faktor yang dapat mempengaruhi kepuasan kerja sebagai berikut:

Tabel 1. Faktor-faktor yang mempengaruhi kepuasan karyawan

\begin{tabular}{|l|l|}
\hline Faktor & Persentase \\
\hline Kompensasi & $19 \%$ \\
\hline Sarana dan prasarana & $9 \%$ \\
\hline Gaya kepemimpinan & $32 \%$ \\
\hline Budaya organisasi & $25 \%$ \\
\hline Lingkungan kerja & $15 \%$ \\
\hline
\end{tabular}

Sumber: Bohlander, S (2013)

Selain lingkungan organisasi, perilaku kepemimpinan manajerpun memainkan peran penting dalam membentuk kepuasan kerja karyawan bagi karyawan (Snell, B, 2013). Hal ini 
dikarenakan bahwa, kepemimpinan dipandang sebagai fungsi manajemen yang berkaitan dengan interaksi sosial (Ratnasari, S dan Sutjahjor, G, 2019), terutama dalam industri layanan jasa kesehatan rumah sakit. Sektor rumah sakit merupakan salah satu organisasi yang bergerak dalam layanan kesehatan untuk memenuhi kebutuhan kesehatan masyarakat (Hoboubi, N dan Choobiner, A, 2017). Penelitian Gandolfi, F dan Stone (2018) menyebutkan bahwa gaya kepemimpinan mempunyai hubungan positif terhadap kepuasan kerja para pegawai. Begitu juga dengan penelitian Wei,H dan Sewell,K (2018) yang menyatakan bahwa lingkungan organisasi juga memiliki hubungan terhadap kepuasan kerja. Kedua penelitian tersebut menujukkan bahwa dua variabel (lingkungan dan kepemimpinan) adalah salah satu faktor yang dapat mempengaruhi kepuasan kerja karyawan dalam organisasi. Namun kedua penelitian tersebut tidak mengkaji mengenai sektor layanan jasa terutama rumah sakit. Selain hal ini, terlihat juga bahwa absensi karyawa yang ada pada rumah sakit Cibabat khususnya pada divisi rekam medis mengalami penurunan pada setiap quartal.

Tabel 2. Absensi karyawan

\begin{tabular}{|c|c|c|c|c|}
\hline \multirow{2}{*}{ Bulan } & \multicolumn{3}{|c|}{ Absensi Karyawan } & \multirow{2}{*}{ Jumlah } \\
\cline { 2 - 5 } & Ijin & Sakit & Tanpa Keterangan & \\
\hline Quatra I 2020 & 10 & 12 & 13 & 35 \\
\hline Quatra II 2020 & 5 & 10 & 11 & 26 \\
\hline Quatra III 2020 & 10 & 9 & 14 & 33 \\
\hline
\end{tabular}

Sumber: Absensi karyawan Rumah Sakit (2020)

Berdasarkan pada data yang diperoleh, bahwa kinerja karyawa rumah sakit dapat dikatakan rendah serta mengalami penurunan. Hal ini juga memberikan arti bahwa kepuasan kerja karyawan mengalami penurunan. Dalam industri rumah sakit, karyawan yang puas akan berkomitmen dalam memberikan perawatan yang lebih baik (Mira, M dan Choong, Y, 2019). Namun demikian, kepuasan karyawanpun akan sangat menurun bahkan tidak loyal apabila dalam organisasi tersebut terdapat lingkungan serta gaya kepemimpinan yang tidak baik. Berdasarkan pada latar belakang, penelitian ini diajukan untuk mengetahui sejaumana pengaruh lingkungan dan gaya kepemimpinan terhadap kepuasan kerja karyawan pada sektor layanan jasa kesehatan rumah sakit di kota Cimahi khususnya pada divisi rekam medis. Makalah ini disusun sebagai berikut: Bagian 1 memberikan pendahuluan untuk penelitian ini, Bagian kedua menyajikan kajian pustakan dan pengembangan hipotesis, Bagian 3 menunjukka desain dan metode penelitian, Bagian 4 pembahasan dan hasil dari uji hipotesisi, bagian 5 memberikan kesimpulan serta peneltitian lebih lanjut.

\section{TINJAUAN PUSTAKA DAN PENGEMBANGAN HIPOTESIS}

\section{Lingkungan Organisasi}

Menurut Hoboubi, N et al (2017) salah satu faktor kepuasan seseorang dalam suatu organisasi dapat dipengaruhi oleh lingkungan dimana ia bekerja. Wei, H dan Sewell,K (2018) mendefinisikan bahwa lingkungan kerja adalah sesuatu yang ada disekita para pekerja yang dapat mempengaruhi dirinya dalam menjalankan tugas yang dibebankan. Lingkungan kerja 
merupakan komponen yang penting ketika karyawan melakukan aktivitas pekerjaannya (Kurniawati, K dan Ramly,M, 2019). Dengan memperhatikan lingkungan kerja yang baik atau menciptakan kondisi kerja yang mampu memberikan motivasi maka akan membawa pengaruh terhadap kinerja karyawan dalam bekerja, dan hal inilah yang dapat menjadi karyawa merasa puas dengan pekerjaannya. Definisi ini memberikan arti bahwa lingkungan kerja adalah sesuatu yang ada disekitar karyawan yang dapat memberikan pengaruh terhadap pekerjaan. Loan, L, T (2020) menyebutkan secara garis besar lingkungan kerja terbagi menjadi dua, yaitu lingkungan kerja fisik dan non fisik. Yang dimaksud dengan lingkungan kerja fisik adalah semua keadaan yang berbentuk fisik yang terdapat disekitar tempat kerja. Adapun yang dimaksud dengan lingkungan kerja non fisik adalah semua keadaan yang terjadi dimana hal ini berkaitan dengan hubungan kerja, baik dengan atasan maupun dengan sesama rekan kerja. Dalam penelitian ini, penulis memfokuskan pada lingkungan kerja non fisik. Hal ini dikarenakan bahwa hubungan rekan kerja atau atasan dan bawahan lebih mendominasi dalam memberikan kepuasan kerja kepada karyawan. Hal ini juga diperkuat oleh penelitian Kurniawaty, K (2019) bahwa lingkungan kerja non fisik memberikan pengaruh terhadap kepuasan karyawan dalam suatu organisasi.

$H_{1}$. Lingkungan kerja berpengaruh terhadap kepuasan kerja karyawan

\section{Gaya Kepemimpinan}

Gandolfi, F dan Stone (2018) berpendapat bahwa gaya kepemimpinan dalam suatu organisasi sangatlah penting sebagai proses mempengaruhi orang sehingga mereka berusaha dengan kemauan dan semangatnya sendiri untuk mencapai tujuan. Gaya kepemimpinan dipandang sebagai kombinasi dari berbagai karakteristik, sifat dan perilaku yang digunakan oleh pemimpin untuk berinteraksi dengan bawahannya. Dewi,N (2020) menganggap kepemimpinan sebagai pola yang terkait dengan perilaku manajerial, yang dirancang untuk mengintegrasikan kepentingan dan efek organisasi atau pribadi untuk mencapai tujuan organisasi. Alblooshi, M (2020) gaya kepemimpinan dapat dikategorikan kedalam empat kategori yaitu gaya kepemimpinan otokratis, demokratif, laissez faire, dan toxit leadership. Nguyen et al (2017) berpendapat bahwa seorang pemimpin harus membutuhkan pemahaman yang mendalam mengenai peran orang-orang dalam kesuksesan organisasi (Gandolfi \& Stone, 2016). Pemimpin merupakan salah seorang yang memiliki peran dalam mempengaruhi setiap karyawan atau bawahan. Menurut Loan, L (2020) seorang pemimpin harus bisa memberikan kepercayaan kepada bawahan dengan kemampuan yang dimiliki untuk bisa menciptakan suatu kerja yang baik, serta memberikan apresiasi dari setiap hasil yang dicapai sehingga karyawan memiliki rasa kepercayaan diri dalam melakukan setiap tugas yang diberikan. Penelitian Alblooshi, M dan Shamsuzzaman (2020) menyebutkan bahwa gaya kepemimpinan dalam organisasi memberikan pengaruh terhadap kepuasan karyawan dalam suatu organisasi.

$H_{2}$. Gaya kepemimpinan berpengaruh terhadap kepuasan kerja karyawan

\section{Kepuasan Kerja Karyawan}

Kepuasan kerja merupakan emosi dan perasaan yang dimiliki seseorang tentang pekerjaannya (Moses dan Fred, 2018). Kepuasan kerja memiliki korelasi dengan retensi serta 
kinerja yang dilakukakan. Menurut Sree, R dan Satyavathi (2017) Kepuasan kerja telah diakui sebagai variabel dalam menjelaskan kinerja organisasi dan niat karyawan berpindah. Menurut Dousin, O dan Collins (2019) salah satu faktor yang bertanggung jawab atas kepuasan dan ketidakpuasan kerja adalah manajemen pada perusahaan itu sendiri serta kemampuan manajer untuk mengidentifikasi faktor-faktor tingkat turnover yang tinggi. Baik dan buruk suatu pekerjaan kemungkinan besar berkontribusi pada pengembangan perasaan kepuasan atau ketidakpuasan karyawan dalam melakukan pekerjaannya. Hoboubi, N (2017) menyebutkan Kepuasan kerja atau ketidakpuasan didasarkan pada faktor-faktor yang berkisar pada lingkungan, budaya, serta gaya kepemimpinan dalam organisasi. Loan, L (2020) menyebutkan bahwa lingkungan organisasi dan gaya kepemimpinan sangat mempengaruhi terhadap kepuasan karyawan. Hingga pada akhirnyan, hal tersebut mengakibatkan turn over yang tinggi serta berdampak pada kepuasan kerja karyawan.

$H_{3}$. Lingkungan kerja dan gaya kepemimpinan berpengaruh terhadap kepuasan kerja karyawan

\section{Kerangka Konseptual Penelitian}

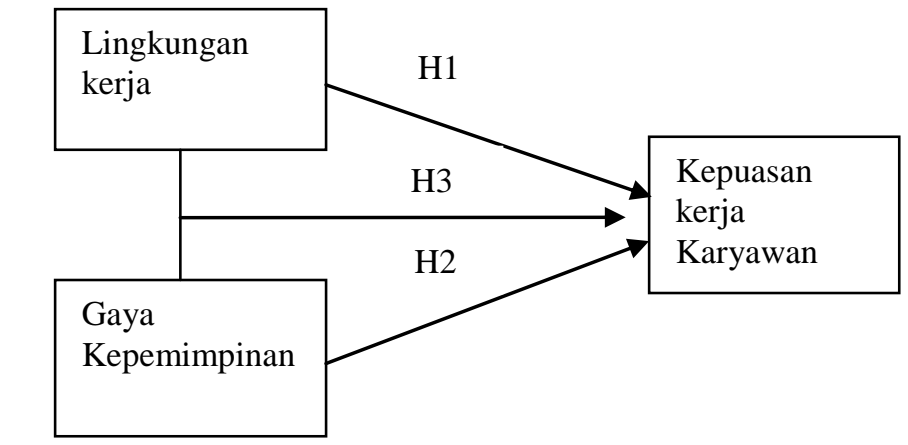

Sumber: Kurniawati, K, Ramly,M (2019); Alonderienen, R (2016)

\section{Gambar 1. Kerangka konseptual}

\section{METODE PENELITIAN}

Penelitian ini dilakukan dengan pendekatan kuantitatif. Pada penelitian ini, 91 sampel yang terdiri dari karyawan rumah sakit pada divisi rekam medis dipilih untuk dijadikan sampel. Metode pengambilan sampel menggunakan teknik purposive sampling. Data primer yang digunakan pada penelitian ini berupa data yang dikumpulkan melalui kuesioner serta wawancara dengan pihak terkait. Sedangkan data sekunder dikumpulkan dari beberapa publikasi jurnal dan textbook. Analisis data yang digunakan adalah analisis statistik deskriptif verifikatif dengan mengadopsi teknik analisis regresi linear berganda dengan menggunakan bantuan sofware SPSS 25 . 


\section{HASIL PENELITIAN DAN DISKUSI}

Data dari tanggapan 91 responden menunjukkan bahwa hasil diperoleh sebagai berikut:

Tabel 3. Profil Responden

\begin{tabular}{|l|l|c|}
\hline \multicolumn{2}{|c|}{ Profil Responden } & Persentase \\
\hline Jenis Kelamin & Laki-laki & $15 \%$ \\
\hline & Perempuan & $85 \%$ \\
\hline Usia & $20-30$ thn & $60 \%$ \\
\hline & $31-40$ thn & $25 \%$ \\
\hline Pendidikan & $>40$ thn & $15 \%$ \\
\hline & S2 & - \\
\hline & S1 & $35 \%$ \\
\hline marital status & D3 & $65 \%$ \\
\hline & Single & $27 \%$ \\
\hline & Married & $65 \%$ \\
\hline
\end{tabular}

Data diolah: 2020

Berdasarkan pada tabel diatas, diperoleh bahwa jenis kelamin perempuan lebih banyak jika dibandingkan dengan laki-laki sebesar $85 \%$. Berdasrkan usia responden bahwa usia yang ada pada kisaran 20 sd 30 lebih banyak dengan perolehan $60 \%$, hal ini menunjukkan bahwa usia tersebut merupakan usia yang produktif. Adapun pendidikan, rata-rata reponden memiliki pendidikan d3 dengan perolehan sebesar $65 \%$.

\section{Analisis Deskriptif}

Tabel 4. Analisis Deskriptif

\begin{tabular}{|l|c|c|c|c|}
\hline \multicolumn{1}{|c|}{ Variabel } & Minimum & Maksimum & Rata-Rata & Keterangan \\
\hline Lingkungan Kerja (X1) & 1 & 5 & 4,04 & Baik \\
\hline Gaya Kepemimpinan (X2) & 2 & 5 & 3,94 & Baik \\
\hline Kepuasan Kerja (Y) & 1 & 5 & 3,98 & Baik \\
\hline
\end{tabular}

Sumber:

Berdasarkan hasil pada tabel 4, menunjukkan bahwa responden dalam penelitian ini memiliki persepsi yang baik. Hasil rata-rata nilai pertanyaan mengenai lingkungan kerja adalah 4,04, gaya kepemimpinan 3,94 dan kepuasan 3,98. Hal ini menunjukkan bahwa setiap variabel penelitian mendapat nilai yang baik.

\section{Uji Validitas.}

Uji validitas setiap variabel terlihat pada. Tabel 4, yang menunjukkan bahwa setiap pernyataan valid

Tabel 5. Uji validitas

\begin{tabular}{|l|l|c|c|c|}
\hline \multicolumn{1}{|c|}{ Variabel } & Pernyataan & R hitung & R tabel & Keterangan \\
\hline \multirow{5}{*}{ Lingkungan kerja } & X1.1 & 0,613 & 0.3 & Valid \\
\cline { 2 - 3 } & X1.2 & 0,537 & & \\
\cline { 2 - 3 } & X1.3 & 0,645 & & \\
\cline { 2 - 3 } & X1.4 & 0,501 & & \\
\hline Gaya Kepemimpinan & X2.1 & 0,628 & 0.3 & Valid \\
\hline
\end{tabular}




\begin{tabular}{|l|l|l|l|l|}
\hline \multirow{5}{*}{\begin{tabular}{l|l|l|} 
Kepuasan Kerja \\
karyawan
\end{tabular}} & X2.2 & 0,548 & \multirow{2}{*}{} & \\
\cline { 2 - 3 } & X2.3 & 0,543 & & \\
\cline { 2 - 3 } & X2.4 & 0,512 & & \\
\cline { 2 - 3 } & Y1.1 & 0,651 & 0.3 & Valid \\
\cline { 2 - 3 } & Y1.3 & 0,587 & & \\
\hline
\end{tabular}

Data diolah: 2020

\section{Tabel 3 Uji reliabilitas}

Uji reliabilitas pada setiap variabel menunjukkan bahwa item-item pernyataan reliabel

Tabel 6. Uji reliabilitas

\begin{tabular}{|l|c|c|}
\hline Variabel & Cronbach Alpha (>0,70) & Keterangan \\
\hline Lingkungan kerja & 0,736 & Reliabel \\
\hline Gaya Kepemimpinan & 0,873 & Reliabel \\
\hline Kepuasan Kerja Karyawan & 0,845 & Reliabel \\
\hline
\end{tabular}

Data diolah: 2020

\section{Uji Multikolinearitas}

Berdasarkan hasil output Spss maka dapat dilihat bahwa nilai menunjukkan bahwa tidak ada masalah dalam hal multikolinearitas antara variabel, hal ini dapat dilihat pada tabel dibawah:

Tabel 6 Multikolinearitas

\begin{tabular}{|c|c|c|c|}
\hline \multicolumn{4}{|c|}{ Coefficients $^{a}$} \\
\hline \multirow{2}{*}{\multicolumn{2}{|c|}{ Model }} & \multicolumn{2}{|c|}{ Collinearity Statistics } \\
\hline & & Tolerance & VIF \\
\hline \multirow[t]{3}{*}{1} & Lingkungan kerja (X1) & .653 & 1.642 \\
\hline & Gaya Kepemimpinan (X2) & .851 & 1.721 \\
\hline & a. dependent variable: Kepuasan kerja karyawan $(\mathrm{Y})$ & & \\
\hline
\end{tabular}

Data diolah: 2020

\section{Uji Koefisien Determinasi}

Tabel 7 Uji Koefisien Determinasi

\section{Model Summary}

\begin{tabular}{|l|r|r|r|r|}
\hline Model & \multicolumn{1}{|c|}{$\mathrm{R}$} & R Square & \multicolumn{1}{|c|}{$\begin{array}{c}\text { Adjusted R } \\
\text { Square }\end{array}$} & $\begin{array}{l}\text { Std. Error of the } \\
\text { Estimate }\end{array}$ \\
\hline 1 &, $789^{\mathrm{a}}$ &, 623 &, 571 &, 341 \\
\hline
\end{tabular}

a. Predictors: (Constant), Lingkungan kerja, Gaya kepemimpinan

b. Dependent Variable: Kepuasan kerja karyawan

Tabel 7 diatas menunjukkan nilai dari Adjusted $R$ Square sebesar 0,571. Hasil tersebut memiliki makna bahwa terdapat pengaruh sebesar 57,1\% lingkungan kerja, gaya kepemimpinan terhadap kepuasan kerja karyawan rumah sakit, dan sisanya 42,9 merupakan variabel lain yang tidak dibahas dalam penelitian ini 


\section{Uji Goodness of Fit}

Uji Goodness of fit menggunakan uji statistic F terhadap model penelitian $Y=\alpha+$ $\beta_{1} X_{1}+\beta_{2} X_{2}+\beta_{3} X_{3}+e$ dengan menggunakan bantuan aplikasi SPSS for Windows diperoleh hasil sebagaimana ditampilkan dalam tabel. Dari tabel hasil uji F diperoleh $\mathrm{F}_{\text {hitung }}$ sebesar 0,720 dengan tingkat yang signifikansinya sebesar 0,000. Karena nilai signifikansi yang diperoleh $0,000<0,05$ maka dapat disimpulkan bahwa model telah memenuhi syarat Goodness of fit. Dengan demikian, model dapat untuk digunakan.

Tabel 8 Hasil Uji Goodness of Fit

\begin{tabular}{|c|c|c|c|c|c|c|}
\hline \multicolumn{7}{|c|}{ ANOVA $^{a}$} \\
\hline & & Sum of Squares & $\mathrm{df}$ & Mean Square & $\mathrm{F}$ & Sig. \\
\hline \multirow[t]{3}{*}{1} & Regression & 5,857 & 2 & 2,928 & ,720 &, $000^{b}$ \\
\hline & Residual & 202,463 & 47 & 4,308 & & \\
\hline & Total & 208,320 & 49 & & & \\
\hline
\end{tabular}

a. Dependent Variable: Kepuasan Kerja Karyawan (Y)

b. Predictors: (Constant), Gaya Kepemimpinan (X2), Lingkungan kerja (X1)

\section{Analisis Regresi Berganda}

Berdasarkan hasil perhitungan yang diperoleh maka dapat dilihat bahwa hasil pengujian analisis regresi berganda dapat dilihat pada tabel dibawah:

Tabel 9 Analisis regresi berganda

Coefficients $^{\mathrm{a}}$

\begin{tabular}{|c|c|c|c|c|c|c|}
\hline \multirow{2}{*}{\multicolumn{2}{|c|}{ Model }} & \multicolumn{2}{|c|}{$\begin{array}{c}\text { Unstandardized } \\
\text { Coefficients }\end{array}$} & \multirow{2}{*}{$\begin{array}{c}\begin{array}{c}\text { Standardized } \\
\text { Coefficients }\end{array} \\
\text { Beta }\end{array}$} & \multirow[b]{2}{*}{$\mathbf{t}$} & \multirow[b]{2}{*}{ Sig. } \\
\hline & & B & Std. Error & & & \\
\hline \multirow[t]{3}{*}{1} & (Constant) & 21,463 & 2,485 & & 8,274 & ,000 \\
\hline & $\begin{array}{l}\text { Lingkungan } \\
\text { kerja }\end{array}$ & ,221 & , 160 & , 126 & 1,821 & ,007 \\
\hline & $\begin{array}{l}\text { Gaya } \\
\text { Kepemimpinan }\end{array}$ & , 408 & , 148 & ,296 & 1,734 &, 017 \\
\hline
\end{tabular}

a. Constant: Kepuasan kerja karyawan

b. Data diolah: 2020

Berdasarakan hasil perolehan dari perhitungan, maka diperoleh nilai konstanta (a) 20,563 serta nilai variabel lingkungan kerja sebesar 0,221 dan nilai variabel gaya kepemimpinan 0,308. Dengan begitu, maka diperoleh persamaan regresi sebagai berikut:

$$
Y=21,463+0,221 X_{1}+0,408 X_{2}
$$

Hal Ini menunjukkan bahwa lingkungan kerja dan gaya kepemimpinan berpengaruh terhadap kepuasan kerja karyawan Rumah sakit di kota Cimahi. 


\section{Uji Normalitas Kolmogorov-Smirnov}

Uji normalitas digunakan untuk mengetahui apakah data dalam penelitian berdistribusi normal atau tidak.

Tabel 10 Hasil Uji Normalitas Kolmogorov-Smirnov

One-Sample Kolmogorov-Smirnov Test

\begin{tabular}{|ll|r|}
\hline & & $\begin{array}{c}\text { Unstandardized } \\
\text { Residual }\end{array}$ \\
\hline $\mathrm{N}$ & Mean & 89 \\
& Std. Deviation &, 0000000 \\
Most Extreme Differences & Absolute & 2,03251846 \\
& Positive &, 083 \\
& Negative &, 052 \\
Test Statistic & &,- 083 \\
Asymp. Sig. (2-tailed) & &, 083 \\
\end{tabular}

Data diolah: 2020

Berdasarkan tabel 10 diatas uji normalitas Kolmogorov-Smirnov terlihat nilai signifikansinya sebesar 0,200>0,05. Maka dapat disimpulkan data tersebut berdistribusi normal.

\section{Pembahasan}

1. Dari hasil Uji Goodness of Fit atau uji $\mathrm{F}$ terlihat nilai $\mathrm{F}_{\text {hitung }}$ sebesar $4,720>\mathrm{F}_{\text {tabel }}$ sebesar 3,103, sehingga diketahui kedua variabel bebas yaitu Lingkungan kerja $\left(\mathrm{X}_{1}\right)$ dan gaya kepemimpinan $\left(\mathrm{X}_{2}\right)$ berpengaruh signifikan terhadap kepuasan kerja karyawan (Y).

2. Dari hasil uji regresi berganda diperoleh persamaan sebagai berikut:

$$
Y=21,463+0,221 X_{1}+0,408 X_{2}
$$

Artinya:

a. Kepuasan Kerja Karyawan Rumah Sakit diperoleh sebesar 21,463yang besarnya tersebut tidak dipengaruhi oleh variabel lingkungan kerja dan gaya kepemimpinan. Akan tetapi besarnya tersebut dipengaruhi variabel lain diluar model.

b. Variabel lingkungan kerja memberikan pengaruh terhadap kepuasan kerja karyawan rumah sakit sebesar 32,1\%. Namun lingkungan kerja yang terjadi dalam penelitian ini akan memberikan efek negatif terhadap kepuasan kerja karyawan rumah sakit. Hal ini dikarenakan sering sekali terjadi konflik emosional yang dapat merubah pandangan karyawan terhadap kepemimpinan yang ada di rumah sakit tersebut.

c. Variabel Gaya Kepemimpinan memberikan pengaruh sebesar 40,8\% terhadap kepuasan kerja karyawan rumah sakit. Artinya gaya kepemimpinan yang baik akan meningkatkan kepuasan kerja karyawan rumah sakit.

\section{KESIMPULAN}


1. Berdasarkan hasil uji $\mathrm{F}$ dapat diketahui bahwa kedua variabel lingkungan organisasi dan gaya kepemimpinan mempunyai pengaruh yang signifikan secara serempak terhadap Y (Kepuasan Kerja Karyawan).

2. Berdasarkan hasil uji regresi berganda, diketahui bahwa variabel bebas yang terdiri dari lingkungan kerja dan gaya Kepemimpinan memiliki pengaruh secara parsial terhadap kepuasan kerja karyawa di rumah sakit kota cimahi. Lingkungan kerja dan Gaya kepemimpinan yang baik memliki pengaruh positif terhadap kepuasan kerja karyawan.

\section{SARAN}

Bagi karyawan rumah sakit di kota Cimahi. lingkungan kerja dan gaya kepemimpinan dapat memberikan dampak pada kepuasan kerja karyawan. Oleh karena itu manajemen atau organisasi harus membangun lingkungan dan gaya kepemimpinan harus dibangun dengan nilai-nilai yang dapat memberikan efek positif sehingga karyawan dapat memberikan timbal balik yang positif terhadap rumah sakit. Bagi Rumah Sakit, selain upaya membangun lingkungan yang baik, variabel gaya kepemimpinan harus menunjukkan sikap dan figur yang baik sehingga karyawan dapat memberikan kinerja yang maksimal terhadap rumah sakit akibat dari kepuasan kerja yang telah terpenuhi.

\section{DAFTAR PUSTAKA}

\section{Jurnal :}

Al Khajeh, E. H. (2018). Leadership styles on organizational performance. Journal of Human Reseources Management Research, 2018, 1-10.

Alblooshi, M., Shamsuzzaman, M., \& Haridy, S. (2020). The relationship between leadership styles and organisational innovation: A systematic literature review and narrative synthesis. European Journal of Innovation Management.

Al-Sada, M., Al-Esmael, B., \& Faisal, M. N. (2017). Influence of organizational culture and leadership style on employee satisfaction, commitment and motivation in the educational sector in Qatar. EuroMed Journal of Business, 12(2), 163-188.

Bombiak, E. (2019). Green human resource management- the latest trend or strategic necessity? Entrepreneurship and Sustainability Issues, 6(4), 1647-1662.

Capnary, M. C., Rachmawati, R., \& Agung, I. (2018). The influence of flexibility of work to loyalty and employee satisfaction mediated by work life balance to employees with millennial generation background in Indonesia startup companies. Business: Theory and Practice, 19, 217-227

Dousin, O., Collins, N., \& Kler, B. K. (2019). Work-Life Balance, Employee Job Performance and Satisfaction Among Doctors and Nurses in Malaysia. International Journal of Human Resource Studies, 9(4), 306.

Dewi, N. N., \& Wibowo, R. (2020). The effect of leadership style, organizational culture and motivation on employee performance. Management Science Letters, 10(9), 20372044. 
Eskiler, E., Ekici, S., Soyer, F., \& Sari, I. (2016). The relationship between organizational culture and innovative work behavior for sports services in tourism enterprises. Physical Culture and Sport. Studies and Research, 69(1), 53-64.

Felipe, C. M., Roldán, J. L., \& Leal-Rodríguez, A. L. (2017). Impact of organizational culture values on organizational agility. Sustainability (Switzerland), 9(12).

Gandolfi, F., \& Stone, S. (2018). Leadership, Leadership Styles, and Servant Leadership. Journal of Management Research, 18(4), 261-269.

Groen, B., van der Voordt, T., Hoekstra, B., \& van Sprang, H. (2019). Impact of employee satisfaction with facilities on self-assessed productivity support. Journal of Facilities Management, 17(5), 442-462.

Hoboubi, N., Choobineh, A., Kamari Ghanavati, F., Keshavarzi, S., \& Akbar Hosseini, A. (2017). The Impact of Job Stress and Job Satisfaction on Workforce Productivity in an Iranian Petrochemical Industry. Safety and Health at Work, 8(1), 67-71.

Kurniawaty, K., Ramly, M., \& Ramlawati. (2019). The effect of work environment, stress, and job satisfaction on employee turnover intention. Management Science Letters, 9(6), 877-886.

Khan, I. U. (2018). The role of organizational justice and culture in relationships between leadership styles and employees’ performance. Dera Ismail Khan, Gomal University.

Loan, L. T. M. (2020). The influence of organizational commitment on employees' job performance: The mediating role of job satisfaction. Management Science Letters, 10(14), 3307-3312.

Moses, S, Fred, P \& Ebezener (2018) Effect Of Work Conflict On Employees Job Satisfaction: The Case Of College Of Distance Education, University Of Cape Coast. European Scientific Journal. Vol.14.

Mira, M. S., Choong, Y. V., \& Thim, C. K. (2019). The effect of HRM practices and employees' job satisfaction on employee performance. Management Science Letters, 9(6), 771-786.

Nguyen, T. T., Mia, L., Winata, L., \& Chong, V. K. (2017). Effect of transformationalleadership style and management control system on managerial performance. Journal of Business Research, 70, 202-213.

Prahyawan, W., \& Akhmadi. (2017). The Impact Of Transactional Leadership Styles And Organizational Culture On Employee Performance Through Motivation As Intervening Variables. Journal Of Business And Management Research Tirtayasa, $1(1), 51-64$.

Putri, R. A. (2018). Leadership Style And Interpersonal Communication Of Employee Satisfaction And It's Effect On The Employee Performance. Jurnal Pendidikan Bisnis Dan Manajemen, 4(3), 108-116. 
Rotimi, I. A, and Hamzat, B. S. (2017). Influence Of Job Satisfaction On Employees' Performance In MTN Nigeria. International Journal Of Emerging Research In Management \&Technology, 6(7), 138 -141.

Ratnasari, S. L., Sutjahjor, G., \& Adam. (2019). Employees' performance: Organizational culture and leadership style through job satisfaction. Humanities and Social Sciences Reviews, 7(5), 597-608.

Sarhan, N., Harb, A., Shrafat, F., \& Alhusban, M. (2020). The effect of organizational culture on the organizational commitment: Evidence from hotel industry. Management Science Letters, 10(1), 183-196.

Sree, R. N. B., \& Satyavathi, R. (2017). Employee job satisfaction. International Journal of Engineering and Management Research, 7(5), 85-94.

Sarinah, L, Loviandi, Cristi, \& Josua (2020) Impact Of Transactional Leadership Style On Employee Job Satisfaction. Tazkya Journal Of Psychology.

Yusuf, F. A. (2020). The effect of organizational culture on lecturers' organizational commitment in private universities in indonesia. International Journal of Higher Education, 9(2), 16-24.

Wei, H., Sewell, K. A., Woody, G., \& Rose, M. A. (2018). The state of the science of nurse work environments in the United States: A systematic review. International Journal of Nursing Sciences. Chinese Nursing Association.

\section{Buku :}

Bakotić, D. (2016). Relationship between job satisfaction and organisational performance. Economic Research-Ekonomska Istrazivanja , 29(1), 118-130. 